\title{
Effect of postextubation high-flow nasal cannula therapy on lung recruitment and overdistension in high-risk patient
}

\author{
Rui Zhang ${ }^{1 \dagger}$, Huaiwu He ${ }^{1 \dagger}$, Long Yun ${ }^{1 *}$ D, Xiang Zhou' ${ }^{1}$ Xu Wang ${ }^{1}$, Yi Chi', Siyi Yuan ${ }^{1}$ and Zhanqi Zhao 2,3
}

\begin{abstract}
Background: Postextubation high-flow nasal cannula (HFNC) is used as a support therapy in high-risk patients in ICU. This study aimed to determine the effects of HFNC therapy on lung recruitment and overdistension assessed by electrical impedance tomography (EIT).
\end{abstract}

Methods: Twenty-four patients who received HFNC within $24 \mathrm{~h}$ after extubation were prospectively enrolled in this study. EIT was used to monitor regional lung ventilation distributions at baseline (conventional oxygen therapy) and three flow rate levels of HFNC therapy $(20,40$, and $60 \mathrm{~L} / \mathrm{min})$. Change of end-expiratory lung impedance $(\Delta \mathrm{EELI})$, regional recruitment (recruited-pixels) and overdistension (overdistended-pixels), and lung strain change were determined by EIT. EIT images were equally divided into four ventral-to-dorsal horizontal regions of interest (ROIs 1, 2, 3, and 4). "Overdistension-by HFNC" due to HFNC is defined as an increase of overdistened-pixels $>10$ than baseline. Patients were divided into two groups: (1) high potential of recruitment (HPR), recruited-pixels $>10$ pixels at $60 \mathrm{~L} / \mathrm{min}$ than baseline, and (2) low potential of recruitment (LPR), recruited-pixels $<10$ pixels at $60 \mathrm{~L} / \mathrm{min}$ than baseline.

Results: When the flow rate gradually increased from baseline to $60 \mathrm{~L} / \mathrm{min}$, a significant and consistent increasing trend of global $\Delta$ EELI (\%) $(p<0.0001)$, recruited-pixels $(p<0.001)$, and overdistended-pixels $(p=0.101)$ was observed. Moreover, the increase of $\Delta \mathrm{EELI}$ was mainly distributed in ROI2 $(p=0.001)$ and ROI3 $(p<0.0001)$. The HPR group $(13 / 24$ patients) had significantly higher recruited-pixels than the LPR group (11/24 patients) at 20, 40, and $60 \mathrm{~L} / \mathrm{min}$. There were no significant differences in $\mathrm{PaO}_{2} / \mathrm{FiO}_{2}, \Delta \mathrm{EELI}(\%)$, and overdistention pixels between the two groups. The HPR group had 13 patients in which no one had "overdistension-by HFNC", and the LPR group had 11 patients in which 4 patients had "Overdistension-by HFNc" (0/13 vs. 4/11, $p=0.017)$.

Conclusions: Using EIT could identify diverse effects of HFNC on lung regional ventilation in postextubation situations. Further study is required to validate using "HFNC effect" based on lung recruitment and overdistension by EIT in clinical practice.

Trial registration: The study was retrospectively registered at www.clinicaltrials.gov (no. NCT04245241).

Keywords: High-flow nasal cannula, Electrical impedance tomography, Lung recruitment, Lung overdistension

\footnotetext{
*Correspondence: iculong_yun@163.com

${ }^{\dagger}$ Rui Zhang and Huaiwu He contributed equally to this work.

'Department of Critical Care Medicine, Peking Union Medical College Hospital, Peking Union Medical College, Chinese Academy of Medical Sciences, 1 Shuaifuyuan, Dongcheng District, Beijing, China

Full list of author information is available at the end of the article
}

(C) The Author(s). 2020 Open Access This article is licensed under a Creative Commons Attribution 4.0 International License, which permits use, sharing, adaptation, distribution and reproduction in any medium or format, as long as you give appropriate credit to the original author(s) and the source, provide a link to the Creative Commons licence, and indicate if changes were made. The images or other third party material in this article are included in the article's Creative Commons licence, unless indicated otherwise in a credit line to the material. If material is not included in the article's Creative Commons licence and your intended use is not permitted by statutory regulation or exceeds the permitted use, you will need to obtain permission directly from the copyright holder. To view a copy of this licence, visit http://creativecommons.org/licenses/by/4.0/ The Creative Commons Public Domain Dedication waiver (http://creativecommons.org/publicdomain/zero/1.0/) applies to the data made available in this article, unless otherwise stated in a credit line to the data. 


\section{Key messages}

- Using EIT could identify the effects of HFNC on lung regional recruitment and overdistension. Moreover, the effect varied among individuals.

- Classification of "HFNC effect" based on lung recruitment/non-recruitment and overdistension/ non-overdistension might be helpful to guide HFNC therapy in post-extubation situations. Further study will be required to validate the meaning of this classification in clinical practice.

\section{Background}

The utilization of high-flow nasal cannula (HFNC) therapy in the ICU has gained great attention as a bridge therapy after early extubation. It has been used as a firstline strategy for extubation patients at a high risk of hypoxemia [1, 2]. Recent studies have shown that HFNC therapy improves respiratory drive and lung mechanics [3] and enhances $\mathrm{CO}_{2}$ removal [4-6]. A number of studies have described low levels of airway pressure associated with increased end-expiratory lung volume and improved oxygenation with HFNC therapy [4, 7-13]. Moreover, HFNC can improve global and regional lung aeration [3, 14]. In all these clinical and physiologic studies, the set HFNC flow rates were extremely heterogeneous, ranging between 15 and $100 \mathrm{~L} / \mathrm{min}[1,8,11,15]$. This may be related to the complexity of the estimated gas distribution of different flow rates and may make it difficult to select an appropriate flow rate for individual patients.

However, Piastra et al. reported uncommon barotrauma using HFNC therapy $\left(2 \mathrm{~L} / \mathrm{kg} / \mathrm{min}, \mathrm{FiO}_{2} 0.6\right)$ in young infants [16]. Thus, the lung injury induced by HFNC therapy should also be carefully considered. Lung overdistension and stress and strain are the primary determinants of ventilatorinduced lung injury [17]. Electrical impedance tomography (EIT) is a noninvasive, non-ionizing bedside method of monitoring impedance changes related to different lung conditions, especially those related to regional ventilation, such as lung regional recruitment and overdistension during PEEP titration in ARDS patients $[18,19]$. To our knowledge, no one has quantified lung regional response (recruitment, overdistension, and cyclic alveolar collapse) to HENC therapy at different flow levels in critically ill patients.

The aims of this study were as follows: (1) to investigate the effects of HFNC on lung recruitment and overdistension by EIT and (2) to explore a potential method of using EIT for optimal HFNC therapy in clinical practice.

\section{Patients and methods}

\section{Patients}

The Institutional Research and Ethics Committee of the Peking Union Medical College Hospital approved this study for human subjects. Written informed consent was obtained from all patients or next of kin before data were included in the study.

When the research team was available, adult critically ill patients who received HFNC therapy within $24 \mathrm{~h}$ after the extubation were enrolled. Local indications of HFNC therapy after extubation were the following: (1) high-risk of acute respiratory failure after extubation, such as major surgery, basic cardiac dysfunction, basic lung dysfunction, and mechanical ventilation $>7$ days, and (2) presentation of occult respiratory failure after extubation $-\mathrm{PaO}_{2} / \mathrm{FiO}_{2}<300, \mathrm{SpO}_{2}<92 \%$, and/or respiration rate $>25 \mathrm{bpm}$. Patients were excluded from the study if they were aged $<18$ years, were pregnant, had a body mass index (BMI) over $50 \mathrm{~kg} / \mathrm{m}^{2}$, had ribcage malformation, or had any contraindication against using EIT monitoring (automatic implantable cardioverter defibrillator, chest skin injury, etc.).

\section{Physiological measurements}

At enrollment, we collected physiological data at baseline, including height and weight, to assess the BMI, APACHEII score, days of intubation, and $\mathrm{PaO}_{2} / \mathrm{FiO}_{2}$ ratio. Respiratory (RR), peripheral oxygen saturation $\left(\mathrm{SpO}_{2}\right), \mathrm{ROX}$ index (ratio of $\mathrm{SpO}_{2} / \mathrm{FiO}_{2}$ to $\mathrm{RR}$ ), and hemodynamic parameters, including heart rate (HR) and mean arterial pressure (MAP), were obtained at different flow rates. Moreover, the inspiratory and expiratory times were derived from the EIT curve, and PI was measured via the patient's finger by using the IntelliVue MP70 monitor (Philips Medical Systems, Boblingen, Germany). The MP70 system calculates the PI as the ratio between the pulsatile component and the nonpulsatile component of the light reaching the light-sensitive cell of the pulse oximetry probe.

\section{Experimental protocol}

The flow rate of HFNC was gradually increased to achieve the preset three levels $(20,40$, and $60 \mathrm{~L} / \mathrm{min})$, and each flow level was maintained for 20 min to maintain a balance of airway pressure. The entire study lasted approximately $80 \mathrm{~min}$. The patient's condition before HFNC therapy was defined as baseline, which also was taken as zero flow rate of HFNC. Moreover, patients were in a semi-recumbent position during the study period. Conditioned medical air $\left(\mathrm{FiO}_{2}\right.$ 0.30) was delivered via an HFNC (Optiflow, Fisher \& Paykel Healthcare, Auckland, New Zealand). The humidifier (MR850, Fisher \& Paykel Healthcare, Auckland, New Zealand) temperature was set to $37^{\circ} \mathrm{C}$, and the air was delivered by medium-sized, silicon nasal cannulae (RT050/051, Fisher \& Paykel Healthcare, Auckland, New Zealand). The subjects were asked to breathe with their mouth closed during the procedure. 


\section{EIT measurements}

EIT measurements were obtained with PulmoVista (Dräger Medical, Lübeck, Germany). During the protocol, a silicone EIT belt with 16 surface electrodes was placed around the patient's thorax in one transverse plane corresponding to the 4th intercostal parasternal space and was then connected to the EIT monitor for bedside visualization. Electrical alternating currents were applied in a sequential rotating process through adjacent electrode pairs. The resulting differences in surface potential between neighboring electrode pairs were measured. The stimulation frequency and amplitude were adjusted automatically by the EIT device to minimize the influence of background noise. EIT measurements were continuously performed at $20 \mathrm{~Hz}$. In addition, the data were digitally filtered using a low-pass filter with a cutoff frequency of $0.67 \mathrm{~Hz}$ to eliminate cardiac-related impedance changes. EIT scans consist of images showing impedance with a $32 \times 32$-color-coded matrix. EIT data were analyzed offline according to a previously described EIT-based algorithm [20].

\section{Analysis and definition of EIT data}

To reduce the heterogeneity of spontaneous breathing, 2 min of continuous EIT data (with representative breaths) was selected for data analysis (data were averaged) at each flow rate $[3,7]$.

Moreover, the change of EELI $(\triangle \mathrm{EELI})$ and the change of TV $(\Delta \mathrm{TV})$ were determined relative to the baseline EELI and TV. The related definitions were the following:

- EIT images were divided into four symmetrical, non-overlapping and ventral-to-dorsal horizontal regions of interest (ROIs), ranging from the gravityindependent areas to the gravity-dependent areas, namely, the ventral (ROI1), mid-ventral (ROI2), mid-dorsal (ROI3), and dorsal (ROI4) regions. Gravity-independent regions were defined as ROI1 + ROI2, and gravity-dependent regions were defined as ROI3 + ROI4 .

- EIT images at end-inspiration and end-expiration were identified. Tidal image $=$ end-inspiration image - end-expiration image [20].

- End-expiration image pixels = all pixels higher than $25 \%$ of the maximum pixel value in the image. Tidal image pixels $=$ all pixels higher than $20 \%$ of the maximum value in the image of tidal breathing [18].

- Recruited regions (pixels) are defined as newly aerated pixels at different flow rates of 20,40 , and $60 \mathrm{~L} / \mathrm{min}$ compared to baseline [20].

- Overdistended regions (pixels) are defined as aerated pixels that did not join in tidal ventilation at the same flow rate [20]. Hence, the overdistended region pixels are equal to "end-expiration image pixels" minus "tidal image pixels".

- $\Delta$ overdistended-pixels $=$ Difference in overdistended pixels between 20/40/60 L/min than baseline; moreover, "overdistension-by HFNC" caused by HFNC was defined as an increase of $\Delta$ overdistended-pixels $>10$ at $60 \mathrm{~L} / \mathrm{min}$ than baseline.

- Tidal recruitment/derecruitment (cyclic alveolar collapse) regions (pixels) are defined by new aerated pixels from tidal variation to end expiration [20].

- Patients were divided into two groups: (1) high potential of recruitment (HPR), recruited-pixels $>10$ pixels at $60 \mathrm{~L} / \mathrm{min}$ than baseline, and (2) low potential of recruitment (LPR), recruited-pixels $<10$ pixels at $60 \mathrm{~L} / \mathrm{min}$ than baseline.

\section{Statistical analysis}

Statistical analyses were performed using Prism 7 (GraphPad Software, San Diego, CA, USA) and the SPSS 24.0 software package (SPSS Inc., Chicago, IL, USA). This is a self-controlled paired study, and the sample size was calculated using the following formula: $n=(\mathrm{Z} 1-a / 2+\mathrm{Z} 1-\beta)^{2} \mathrm{Sd}^{2} /(\mu \mathrm{t}-\mu \mathrm{c})^{2}$

where $\alpha$ is $0.05, \beta$ is 0.1 , and $\mathrm{Sd}$ is the standard deviation of the difference before and after the HENC intervention. $\mu \mathrm{t}$ - $\mu \mathrm{c}$ is the difference between the follow-up and baseline groups. The sample size was estimated based on $\triangle E E L I$ (\%) [3]. The $\mathrm{mt}$ (SD) and mc (SD) were 74 (174) and 230 (237) based on a previous study, respectively, with a correlation coefficient of 0.6. The minimum sample size to obtain a study power of $90 \%$ was 18 pairs. The MannWhitney test was used for comparisons of groups (HPR group vs. LPR group). Normal distribution was assessed with Kolmogorov-Smirnov normality test. Normally distributed results are presented as mean \pm SD whereas non-normally distributed results are presented as median (25th-75th percentile). Comparisons of the trends of the related parameters according to the different flow rates were performed using a General Linear Model Repeated Measures (GLMRM) [21, 22]. This model is an extension of the classical ANOVA, which allows handling both fixed effect (different flow) and random effect (patient). GLMRM takes into account the correlation between multiple measurements on one patient and thus the estimated marginal means were adjusted for the covariates and the trends of related EIT parameters corresponding to the different flow. When Mauchly's test of sphericity is not demanded ( $p<$ 0.05), Epsilon (Greenhouse-Geisser) was used for the corrected test [23]. All statistics were two-tailed, and a $p$ value of less than 0.05 was considered to be significant.

\section{Results}

From May 2018 to July 2019, a total of 24 patients were enrolled. The main characteristics of the patients are 
summarized in Table 1 . The mean patient age was $66 \pm$ 11 , and 10/24 (53\%) were men. Moreover, the mean days of mechanical ventilation before extubation was $5 \pm 3$. Twenty-two postoperative patients were intubated and mechanically ventilated at the beginning of anesthesia. The other two patients received invasive ventilation because of respiration failure.

\section{Effects of HFNC therapy on $\triangle E E L I$ and lung recruitment,} overdistension, and tidal recruitment at different flow rates The trend of global $\triangle$ EELI significantly increased $(p<0.0001)$. The increased gas volume was mainly distributed in ROI2 $(p=0.001)$ and ROI3 $(p<0.0001)$, but the trend in ROI1 $(p=0.131)$ and ROI4 $(p=0.345)$ was not significant from baseline to $60 \mathrm{~L} / \mathrm{min}$ flow rate (Fig. 1).

The recruitment regions at flow rates of 20,40 , and $60 \mathrm{~L} / \mathrm{min}$ were $5(5,17), 9(1,27)$, and $11(1,22)$ pixels $(p<0.0001)$, respectively. Moreover, the global and regional $\Delta \mathrm{TV}$, overdistended pixels, and tidal recruitment /derecruitment pixels did not change significantly with the introduction of HFNC therapy compared to baseline (Table 2).

\section{Effects of HFNC therapy on respiratory and hemodynamic parameters}

Regarding hemodynamic parameters, no significant changes were observed during the study phases (Table 3 ). Moreover, inspiration $(p=0.345)$ and expiration times $(p=0.967)$, ROX index $(p=0.120)$, and RR $(p=0.144)$ remained stable over all study phases. However, a significant change trend of $\mathrm{SpO}_{2}(p=0.029)$ was found during the various flow rate change.

\section{Differences between HPR and LPR groups}

Thirteen patients could be categorized to the HPR group (in which 12 patients were postoperative), and 11 patients to the LPR group (in which 10 patients was postoperative). Baseline characteristics of HPR and LPR groups are compared in Table 4. There were no significant differences in $\mathrm{PaO}_{2} / \mathrm{FiO}_{2}, \mathrm{ROX}$ index, and days of intubation between these two groups at baseline.

Table 1 Main characteristics of the study population

\begin{tabular}{|c|c|c|c|c|c|c|c|c|}
\hline Pts & Age & $\mathrm{F} / \mathrm{M}$ & BMl & APACHE-II & Admission category & Days of intubation & $\mathrm{PaO}_{2} / \mathrm{FiO}_{2}$ & $\mathrm{PaCO}_{2}(\mathrm{mmHg})$ \\
\hline 1 & 63 & $M$ & 27 & 11 & Thoracic operation & 7 & 375 & 36 \\
\hline 2 & 63 & $\mathrm{~F}$ & 28 & 13 & Abdominal operation & 4 & 375 & 36 \\
\hline 3 & 77 & $\mathrm{~F}$ & 22 & 11 & Thoracic operation & 4 & 291 & 35 \\
\hline 4 & 67 & M & 27 & 8 & Cardiosurgery & 4 & 235 & 36 \\
\hline 5 & 68 & M & 17 & 15 & Cardiosurgery & 9 & 181 & 36 \\
\hline 6 & 53 & M & 24 & 7 & Cardiosurgery & 9 & 269 & 36 \\
\hline 7 & 82 & M & 24 & 15 & Cardiosurgery & 7 & 323 & 36 \\
\hline 8 & 81 & $\mathrm{~F}$ & 24 & 7 & Abdominal operation & 3 & 303 & 47 \\
\hline 9 & 67 & M & 28 & 16 & Abdominal operation & 3 & 308 & 36 \\
\hline 10 & 32 & M & 18 & 6 & Thoracic operation & 2 & 184 & 42 \\
\hline 11 & 80 & $\mathrm{~F}$ & 18 & 15 & Cardiosurgery & 7 & 275 & 50 \\
\hline 12 & 73 & M & 28 & 21 & Abdominal operation & 7 & 417 & 53 \\
\hline 13 & 63 & $\mathrm{~F}$ & 25 & 11 & Abdominal operation & 5 & 325 & 30 \\
\hline 14 & 67 & M & 22 & 9 & Abdominal operation & 5 & 295 & 50 \\
\hline 15 & 63 & $\mathrm{~F}$ & 22 & 9 & Abdominal operation & 1 & 161 & 35 \\
\hline 16 & 65 & M & 19 & 12 & Thoracic operation & 10 & 275 & 38 \\
\hline 17 & 68 & $\mathrm{~F}$ & 25 & 10 & Thoracic operation & 10 & 182 & 39 \\
\hline 18 & 65 & $\mathrm{~F}$ & 23 & 15 & Abdominal operation & 3 & 155 & 38 \\
\hline 19 & 65 & $\mathrm{~F}$ & 23 & 12 & Other & 4 & 220 & 37 \\
\hline 20 & 66 & M & 22 & 14 & Abdominal operation & 5 & 271 & 38 \\
\hline 21 & 68 & M & 24 & 16 & Abdominal operation & 6 & 284 & 40 \\
\hline 22 & 66 & M & 23 & 12 & Thoracic operation & 5 & 273 & 41 \\
\hline 23 & 64 & M & 20 & 10 & Cardiosurgery & 4 & 264 & 39 \\
\hline 24 & 66 & M & 26 & 14 & Other & 5 & 276 & 43 \\
\hline Summary & $66 \pm 11$ & $9 / 15$ & $23 \pm 3$ & $12 \pm 4$ & $22 / 24$ postoperative pts & $5 \pm 3$ & $266 \pm 69$ & $40 \pm 6$ \\
\hline
\end{tabular}




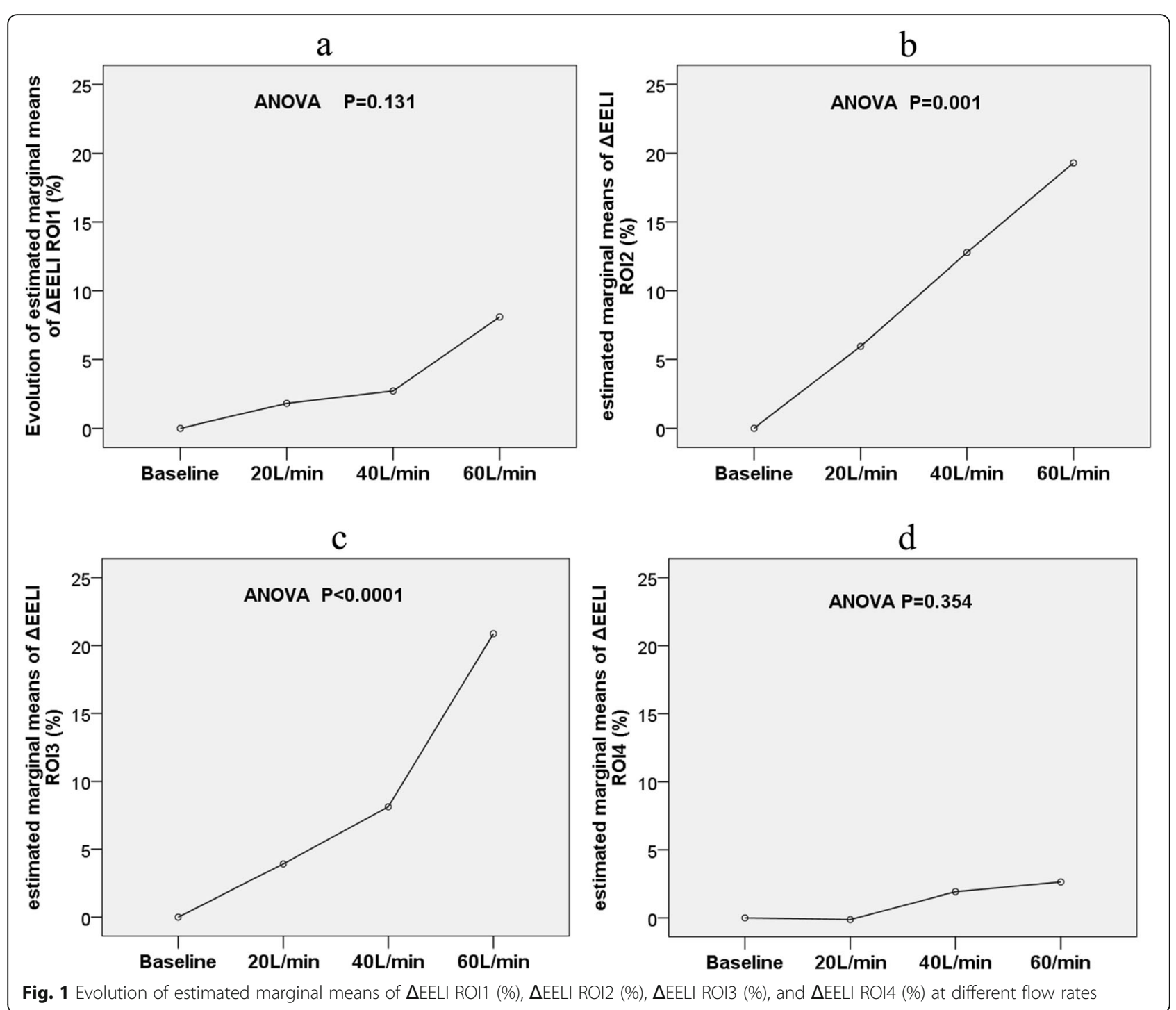

Evolutions of related parameters between HPR and LPR groups at different flows are shown in Table 5 . The estimated marginal means of recruited-pixels at different flow rates between HPR and LPR groups are shown in Fig. 2. The HPR group had a significant higher recruited regions (pixels) than the LPR group at different flow rates $(20 \mathrm{~L} /$ min, $12(7,24)$ vs. $0(0,5) p=0.001 ; 40 \mathrm{~L} / \mathrm{min}, 17(10,41)$ vs. $0(0,8) p=0.002$; and $60 \mathrm{~L} / \mathrm{min}, 20(16,42)$ vs. $0(0,8) p<$ $0.0001)$. There was no significance in overdistensionpixels, tidal recruitment/derecruitment (pixels), and $\Delta$ overdistension-pixels (from baseline) between the two groups. However, the LPR group had a significantly higher percentage of "overdistension-by HFNC" patients than the HPR group (0/13 vs. $4 / 11, p=0.017)$.

\section{Discussion}

In extubated patients within $24 \mathrm{~h}$ of undergoing HFNC therapy, in addition to improving the EELI and lung aeration distribution, a high flow rate also induces regional recruitment and overdistension. However, those effects varied among individuals.

\section{Effects of HFNC therapy on lung recruitment, overdistension, and tidal recruitment}

As shown in a previous study, HFNC may induce lung injury barotraumas in infants [16]. In our study, we found that HFNC therapy may induce overdistension, which may be related to the lung injury. Additionally, compared to baseline, HFNC therapy could decrease pulmonary atelectasis and increase overdistension. Meanwhile, tidal recruitment/derecruitment (also present in healthy lungs [24]), which reflects the potential of lung recruitment, was not decreased significantly by HFNC therapy. Furthermore, we distributed all patients into two types from $0 \mathrm{~L} / \mathrm{min}$ to $60 \mathrm{~L} / \mathrm{min}$ : (a) in HPR, thirteen patients showed recruitment (mainly in the dorsal region) with decreased tidal recruitment/derecruitment and 
Table 2 Evolution of ElT-related parameters at different flow rates

\begin{tabular}{|c|c|c|c|c|c|c|}
\hline Variables & Baseline & $20 \mathrm{~L} / \mathrm{min}$ & $40 \mathrm{~L} / \mathrm{min}$ & $60 \mathrm{~L} / \mathrm{min}$ & Trend- $p$ & $\begin{array}{l}\text { Mauchly's test of } \\
\text { sphericity } p \text { value }\end{array}$ \\
\hline$\Delta$ EELIgl (\%) & Baseline & $7.19(-5.12,18.66)$ & $10.61(-3.42,41.99)^{a, b}$ & $26.32(10.68,60.75)^{a, b, c}$ & $<0.0001^{*}$ & 0.046 \\
\hline$\Delta$ EELI ROI1 (\%) & Baseline & $0.32(-0.07,2.74)$ & $0.18(0.00,3.05)$ & $1.61(0.00,4.60)$ & 0.131 & 0.000 \\
\hline$\Delta$ EELI ROI2 (\%) & Baseline & $2.12(-3.21,7.35)$ & $8.6(-1.42,18.19)^{a, b}$ & $16.15(4.00,27.90)^{a, b}$ & $0.001^{*}$ & 0.000 \\
\hline$\Delta$ EELI ROI3 (\%) & Baseline & $2.52(-3.77,6.23)$ & $3.94(-3.04,14.48)$ & $14.29(4.01,32.26)^{a, b, c}$ & $<0.0001^{*}$ & 0.462 \\
\hline$\Delta$ EELI ROI4 (\%) & Baseline & $0.21(0.00,0.40)$ & $0.00(0.00,1.77)$ & $0.33(0.00,2.43)$ & 0.345 & 0.000 \\
\hline$\Delta \mathrm{VTgl}(\%)$ & Baseline & $6.40(-12.27,22.74)$ & $5.66(-8.60,19.78)$ & $3.71(-3.29,15.29)$ & 0.095 & 0.066 \\
\hline$\Delta V T$ ROI1 (\%) & Baseline & $0.41(-1.13,1.72)$ & $0.43(-0.27,2.10)$ & $0.72(0.00,2.53)$ & 0.069 & 0.000 \\
\hline$\Delta V T$ ROI2 (\%) & Baseline & $1.66(-5.01,13.19)$ & $4.43(-2.17,12.41)$ & $1.93(-2.50,13.52)$ & 0.077 & 0.003 \\
\hline$\Delta \mathrm{VT}$ ROI3 (\%) & Baseline & $2.97(-4.07,8.10)$ & $0.53(-4.20,8.00)$ & $0.12(-9.02,10.20)$ & 0.446 & 0.004 \\
\hline$\Delta V T$ ROI4 (\%) & Baseline & $0.00(-1.19,0.64)$ & $0.00(-0.80,1.23)$ & $0.00(-0.54,1.24)$ & 0.354 & 0.000 \\
\hline Gl index (\%) & $0.47 \pm 0.22$ & $0.47 \pm 0.21$ & $0.47 \pm 0.23$ & $0.46 \pm 0.20$ & 0.693 & 0.000 \\
\hline RVD index (\%) & $4.34(3.39,9.65)$ & $5.66(3.74,11.82)$ & $5.52(3.51,9.59)$ & $5.89(3.82,8.34)$ & 0.191 & 0.000 \\
\hline Recruited pixels & Baseline & $5(5,17)^{a, b}$ & $9(1,27)^{a, b}$ & $11(1,22)^{a, b}$ & $0.0001^{*}$ & 0.000 \\
\hline Overdistended pixels & $14(8,30)$ & $13(5,28)$ & $13(3,31)$ & $15(6,32)$ & 0.101 & 0.000 \\
\hline $\begin{array}{l}\text { Tidal recruitment/ } \\
\text { derecruitment pixels }\end{array}$ & $12(7,41)$ & $9(1,16)$ & $16(8,33)$ & $11(4,16)$ & 0.124 & 0.031 \\
\hline
\end{tabular}

$p$ value by one-way analysis of variance (ANOVA) for repeated measures

$\triangle E E L /$ change of end-expiratory lung impedance, $\triangle V T$ change of tidal variation, gl global, $R O /$ region of interest, $G /$ global inhomogeneity, $R V D$ regional ventilation delay

av. baseline, $p<0.05$

bs. $20 \mathrm{~L} / \mathrm{min}, p<0.05$

cvs. $40 \mathrm{~L} / \mathrm{min}, p<0.05$

${ }^{*} p<0.05$

without lung overdistension and (b) in LPR, seven patients showed neither recruitment nor overdistension and four patients showed overdistension (mainly in the ventral region) without lung recruitment. Thus, patients classified as type HPR may have a greater potential for recruitment and a lower risk of overdistension, which indicates that HFNC therapy may benefit these patients and that higher flow rates may be required. Patients classified as type LPR may have limited potential for recruitment and a higher risk of hyperinflation, which indicates that HFNC therapy may induce lung injury and should be used cautiously and that the flow rate should be reduced. Moreover, higher flow rates may induce lung recruitment and may lead to hyperinflation in small patients of type LPR, which requires further research. Therefore, HFNC therapy is likely to be beneficial to most patients but can induce lung injury in a small proportion of patients; thus, the flow rate should be selected cautiously among different patients.

Table 3 Change of respiratory and hemodynamics parameters at different flow rates

\begin{tabular}{|c|c|c|c|c|c|c|}
\hline Variables & $0 \mathrm{~L} / \mathrm{min}$ & $20 \mathrm{~L} / \mathrm{min}$ & $40 \mathrm{~L} / \mathrm{min}$ & $60 \mathrm{~L} / \mathrm{min}$ & Trend- $p$ & $\begin{array}{l}\text { Mauchly's test of } \\
\text { sphericity } p \text { value }\end{array}$ \\
\hline $\mathrm{SPO}_{2}(\%)$ & $97 \pm 2$ & $98 \pm 2$ & $98 \pm 2$ & $98 \pm 2$ & $0.029^{*}$ & 0.326 \\
\hline RR (bpm) & $22 \pm 6$ & $20 \pm 4$ & $20 \pm 3$ & $21 \pm 5$ & 0.144 & 0.060 \\
\hline ROX index & $22.41 \pm 5.38$ & $23.88 \pm 5.20$ & $23.54 \pm 4.35$ & $22.20 \pm 4.34$ & 0.120 & 0.598 \\
\hline Inspiration time(s) & $1.48 \pm 0.34$ & $1.61 \pm 0.56$ & $1.54 \pm 0.40$ & $1.55 \pm 0.42$ & 0.345 & 0.891 \\
\hline Expiration time (s) & $1.72 \pm 0.59$ & $1.71 \pm 0.48$ & $1.72 \pm 0.46$ & $1.78 \pm 0.65$ & 0.967 & 0.755 \\
\hline MAP (mmHg) & $86 \pm 10$ & $86 \pm 10$ & $87 \pm 8$ & $87 \pm 8$ & 0.358 & 0.147 \\
\hline HR (bpm) & $90 \pm 14$ & $89 \pm 13$ & $89 \pm 14$ & $88 \pm 13$ & 0.338 & 0.000 \\
\hline PI & $1.9 \pm 1.2$ & $2.0 \pm 1.2$ & $1.6 \pm 1.0$ & $1.9 \pm 1.1$ & 0.635 & 0.000 \\
\hline
\end{tabular}

$\mathrm{SPO}_{2}$ peripheral oxygen saturation, $R R$ respiratory rate, $H R$ heart rate, $M A P$ mean arterial pressure, $P I$ peripheral perfusion index

$\mathrm{ROX}$ index $=$ (Respiratory rate-OXygenation) index $=$ the ratio of $\mathrm{SpO}_{2} / \mathrm{FiO}_{2}$ to RR

$p$ value by one-way analysis of variance (ANOVA) for repeated measures

${ }^{*} p<0.05$ 
Table 4 Comparison baseline date in high potential of recruitment (HPR) and low potential of recruitment (LPR) groups

\begin{tabular}{llll}
\hline Variables & HPR group, $N=13$ & LPR group, $N=11$ & $p$ value \\
\hline Age & $65 \pm 12$ & $68 \pm 5$ & 1.000 \\
$\mathrm{~F} / \mathrm{M}$ & $4 \mathrm{~F} / 9 \mathrm{M}$ & $6 \mathrm{~F} / 5 \mathrm{M}$ & 0.239 \\
$\mathrm{BMI}$ & $23 \pm 4$ & $24 \pm 2$ & 0.910 \\
APACHE-II & $12 \pm 3$ & $12 \pm 4$ & 0.649 \\
Days of intubation & $6 \pm 4$ & $6 \pm 2$ & 1.000 \\
$\mathrm{PaO}_{2} / \mathrm{FiO}_{2}$ & $284 \pm 74$ & $257 \pm 59$ & 0.331 \\
$\mathrm{PaCO}_{2}$ (mmHg) & $40 \pm 7$ & $39 \pm 4$ & 0.955
\end{tabular}

$B M I$ body mass index $\left(\mathrm{kg} / \mathrm{m}^{2}\right)$, APACHE-II Acute Physiology and Chronic Health Evaluation $\mathrm{II}_{1} \mathrm{FiO}_{2}(\%)$ fraction of inspired $\mathrm{O}_{2}, M$ male, $\mathrm{F}$ female

\section{Effects of HFNC therapy on lung strain change}

High values of dynamic lung strain (lung deformation caused by tidal volume) and static lung strain (lung deformation caused by positive end-expiratory pressure (PEEP)) are associated with lung injury [25-27]. However, little is known regarding the influence of flow rates on lung strain during HFNC therapy. EIT has been used to evaluate the lung regional effects of HFNC on change of global and regional end-expiratory lung impedance (EELI) [20, 28], along with change of tidal variation $(\Delta T V)$ [29]. Protti et al. showed that in an animal model, for the same global strain, a large static strain is less harmful than a large dynamic strain [19]. In the present study, lung strain could also be deduced by the related

Table 5 Change parameter of High potential of recruitment (HPR) group vs Low potential of recruitment (LPR) group at different follow

\begin{tabular}{|c|c|c|c|c|c|c|}
\hline Variables & Baseline & $20 \mathrm{~L} / \mathrm{min}$ & $40 \mathrm{~L} / \mathrm{min}$ & $60 \mathrm{~L} / \mathrm{min}$ & Trend-p & $\begin{array}{l}\text { Mauchly's test of } \\
\text { sphericity } p \text { value }\end{array}$ \\
\hline \multicolumn{7}{|l|}{$\Delta \mathrm{EELIgl}(\%)$} \\
\hline HPR group & Baseline & $7.03(-4.49,21.30)$ & $30.66(0.33,47.35)^{a, b}$ & $32.31(10.51,102.96)^{a, b}$ & 0.007 & $<0.0001$ \\
\hline LPR group & Baseline & $7.46(-7.67,17.80)$ & $5.56(-9.20,28.96)$ & $43.95(11.53,71.69)$ & 0.003 & 0.754 \\
\hline \multicolumn{7}{|l|}{$\Delta \mathrm{VTgl}(\%)$} \\
\hline HPR group & Baseline & $9.98(-1.13,21.14)$ & $11.62(-8.21,20.99)$ & $4.27(-6.75,16.14)$ & 0.194 & 0.023 \\
\hline LPR group & Baseline & $4.80(-25.12,41.99)$ & $1.64(-9.57,20.06)$ & $0.12(-3.42,38.45)$ & 0.305 & 0.242 \\
\hline \multicolumn{7}{|c|}{ Recruitment region (pixels) } \\
\hline HPR group & Baseline & $12(7,24)^{\mathrm{a}, \mathrm{q}}$ & $17(10,41)^{\mathrm{a}, \mathrm{b}, \mathrm{q}}$ & $20(16,42)^{a, b, c, q}$ & $<0.0001$ & 0.013 \\
\hline LPR group & Baseline & $0(0,5)$ & $0(0,8)$ & $0(0,8)$ & 0.305 & 0.242 \\
\hline \multicolumn{7}{|c|}{ Overdistension (pixels) } \\
\hline HPR group & $10(5,31)$ & $10(5,30)$ & $11(1,33)$ & $13(3,33)$ & 0.456 & 0.003 \\
\hline LPR group & $16(9,22)$ & $18(6,27)$ & $22(4,28)$ & $16(8,26)$ & 0.159 & 0.006 \\
\hline \multicolumn{7}{|c|}{$\Delta$ overdistension (pixels) } \\
\hline HPR group & Baseline & $1(-2,4)$ & $1(-1,6)$ & $3(1,9)$ & 0.456 & 0.003 \\
\hline LPR group & Baseline & $1(-4,8)$ & $1(-4,10)$ & $4(-1,7)$ & 0.159 & 0.006 \\
\hline \multicolumn{7}{|c|}{$\begin{array}{l}\text { Tidal recruitment/ } \\
\text { derecruitment (pixels) }\end{array}$} \\
\hline HPR group & $15(4,38)$ & $8(0,15)$ & $15(1,33)$ & $5(2,18)$ & 0.096 & 0.77 \\
\hline LPR group & $11(7,51)$ & $10(7,27)$ & $19(10,33)$ & $12(6,13)$ & 0.572 & 0.08 \\
\hline \multicolumn{7}{|l|}{ RR (bpm) } \\
\hline HPR group & $21(19,25)$ & $20 \pm 3$ & $20 \pm 3$ & $21 \pm 4$ & 0.029 & 0.390 \\
\hline LPR group & $20(17,25)$ & $21 \pm 5$ & $20 \pm 3$ & $23 \pm 5$ & 0.473 & 0.270 \\
\hline \multicolumn{7}{|l|}{ ROX index } \\
\hline HPR group & $22 \pm 4$ & $24 \pm 4$ & $23 \pm 4$ & $23 \pm 5$ & 0.065 & 0.089 \\
\hline LPR group & $23 \pm 7$ & $23(19,28)$ & $24 \pm 5$ & $21 \pm 4$ & 0.252 & 0.664 \\
\hline \multicolumn{7}{|l|}{$\mathrm{SPO}_{2}(\%)$} \\
\hline HPR group & $97 \pm 2$ & $97 \pm 2$ & $98 \pm 2$ & $97 \pm 2$ & 0.211 & 0.259 \\
\hline LPR group & $97(95,100)$ & $98 \pm 2$ & $99(98,100)$ & $98(97,100)$ & 0.197 & 0.171 \\
\hline
\end{tabular}

vs. baseline, $p<0.05$;

bs. $20 \mathrm{~L} / \mathrm{min}, p<0.05$

cvs. $40 \mathrm{~L} / \mathrm{min}, p<0.05$;

" $p<0.05$ for HPR vs. LPR at the same flow 


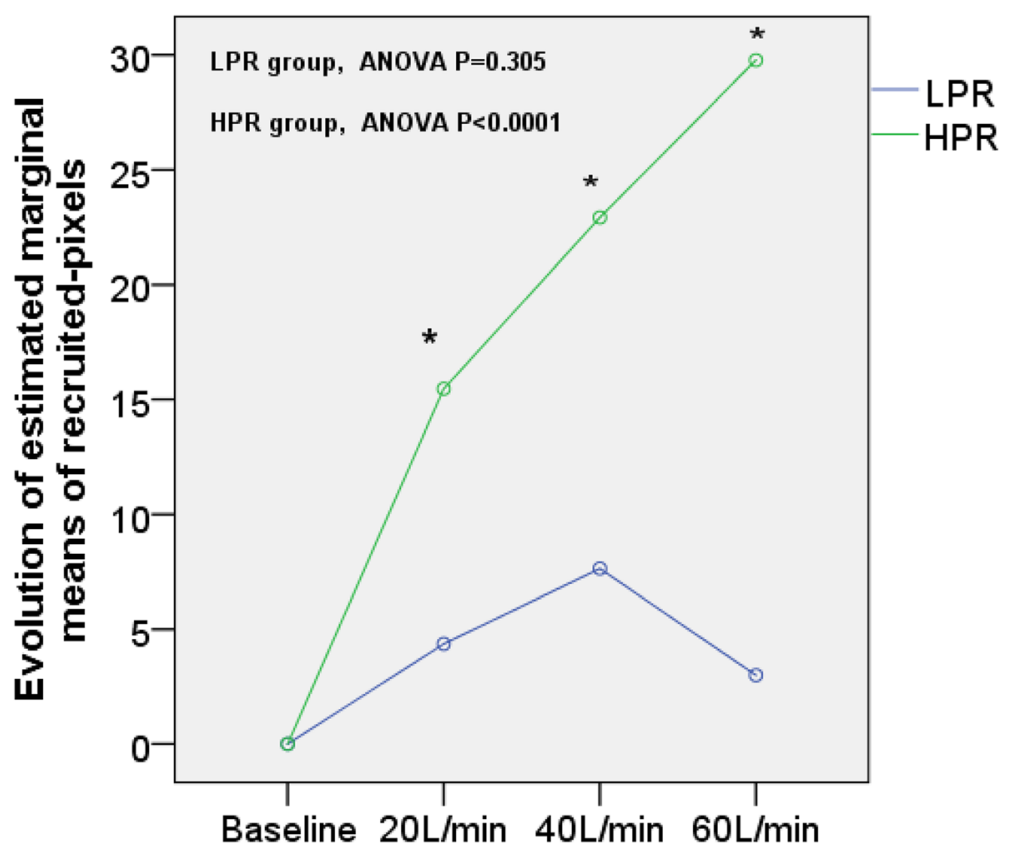

Fig. 2 Evolution of estimated marginal means of recruited-pixels at different flow rates between the HPR and LPR groups. ${ }^{*} p<0.05$, HPR vs. LPR at the same flow rate

EIT parameters (deduction procedure was documented in the online Additional file 1). Given a stable unchanged tidal volume, patients classified as HPR (type HPR, with lung recruitment while receiving HFNC therapy) may have lower dynamic and static lung strain, and patients classified as LPR (types LPR, without lung recruitment while receiving HFNC therapy) have unchanged dynamic lung strain and higher static lung strain, meaning that these patients may have a higher risk of lung injury. Therefore, HFNC therapy may be beneficial for some patients (HPR) by inducing lung recruitment without causing overdistension and may be harmful for patients (LPR) who do not show lung recruitment while receiving HFNC therapy, which may be a foundation for daily clinical flow rate selection.

\section{Effects of HFNC therapy on lung aeration distribution}

Previous studies showed that HFNC may increase the lung volume (EELI) [3, 14]; we also found the same result. Furthermore, we also found that early extubated patients exhibited heterogeneity in the gas distribution between the gravity-independent and gravity-dependent lung regions because of atelectasis in the gravitydependent region. In addition, as the flow rate increased, the EELI of the gravity-dependent region also increased due to recruitment. Moreover, the high flow reopened the medial-ventral and medial-dorsal regions of the lung, showing heterogeneity, mainly because of the limited airway pressure of HFNC therapy (Parke et al. observed that for each increase of $10 \mathrm{~L} / \mathrm{min}$ in the flow rate, the mean airway pressure increased by $0.69 \mathrm{~cm} \mathrm{H}_{2} \mathrm{O}$ [24]) Thus, it is necessary to monitor the gas distribution to avoid ventilation heterogeneity and to select an appropriate flow rate when using HFNC therapy.

\section{Effects of HFNC therapy on hemodynamics and respiratory parameters}

Regarding hemodynamics, we did not find obvious differences among the flow rates, meaning that $20 \mathrm{~min}$ of HFNC therapy may have little influence on hemodynamics. Moreover, several studies conducted in patients with high baseline RR ( $25 \pm 3$ breaths/min) $[4,9]$ have shown that HFNC therapy may improve the breathing pattern. In addition, the ROX index also was used to assess the effect of HFNC therapy and predict the outcome of HFNC [30-32]. However, we did not find such an effect (decrease of RR and increase of ROX index) of HFNC in the present study. Several potential reasons are the following: (a) Most of the patients were at relatively normal respiratory status without obvious hypoxia $\left(\mathrm{SpO}_{2} 97 \pm 2 \%, \mathrm{RR} 22 \pm 6 \mathrm{bpm}\right)$ at the baseline. In the present study, the primary aim of using high-flow nasal cannula therapy to prevent respiratory failure in a high-risk patient; (b) the inability of the RR (approximately 20 breaths/min) to be changed in such a short time period (20 $\min )$.

\section{Study strengths and limitations}

Our study needs to be interpreted within the context of its strengths. The greatest interest of this study is that a heterogeneous response to different HFNC flows was 
found in this study. Marui et al. reported that an increasing HFNC flow rate progressively decreased inspiratory effort and improved lung aeration, dynamic compliance, and oxygenation in patients with acute hypoxemic respiratory failure [3]. However, some contrary results were reported in different studies using HFNC for post-extubation patients. Corley et al. found that HFNC did not improve atelectasis, oxygenation, respiratory rate, or dyspnea, nor did it reduce rates of failure of allocated therapy in recently extubated obese patients [33]. Maggiore et al. showed that HFNC improved oxygenation, comfort, and the reintubation rate in the postextubation setting [8]. Our study also supported the idea that HFNC should be of benefit to some selected patients rather than to all patients [34]. In the present study, different patients had different responses to HFNC: 13 patients showed recruitment without overdistension, 7 patients showed neither recruitment nor overdistension, and 4 patients showed non-recruitment with overdistension. These results may be helpful for clinicians to select appropriate flow rates. However, how exactly to use the EIT approach to (1) decide if a patient should receive HFNC and (2) titrate an optimal flow rate for those who need HFNC will require further research. Based on the implications of these findings, a conceptual schematic for using EIT guide HFNC therapy is presented in Fig. 3.

Several limitations should be acknowledged. First, the study period may be considered to be not long enough to evaluate other relevant clinical outcomes. Second, EIT images display approximately one-third the area of the lungs; therefore, they cannot be used to measure lung volume changes along the vertical axis. Nevertheless, previous studies have shown good agreement between the findings of EIT and those of other reference methods that measure the whole lung volume [35]. Third, while HFNC therapy may induce both lung recruitment and overdistension in some patients at the same time, this phenomenon was not reproduced in our study because the pressure produced by HFNC therapy was large enough. However, for the safety of the patients, we did not choose flow rates higher than $60 \mathrm{~L} / \mathrm{min}$. Fourth, our study compared different flow rates in an effort to assess an optimal flow rate (induce recruitment with minimal overdistension), but the data were not conclusive; thus, further study is required. Moreover, using recruited-pixels $>10$ as regional lung recruitment and overdistendedpixels $>10$ as regional overdistension might be arbitrary; thus, further study is required to validate the related cutoff values. However, we showed lung recruitment, overdistension, and tidal recruitment/derecruitment at baseline and at different flow rates, and HFNC for $20 \mathrm{~min}$ was able to decrease the dynamic and static lung strain in some patients. Fifth, working of breathing (WOB) and diaphragm protection were not measured in the present study. Reduction of WOB and diaphragm protection might be more relevant than lung recruitment during the HFNC

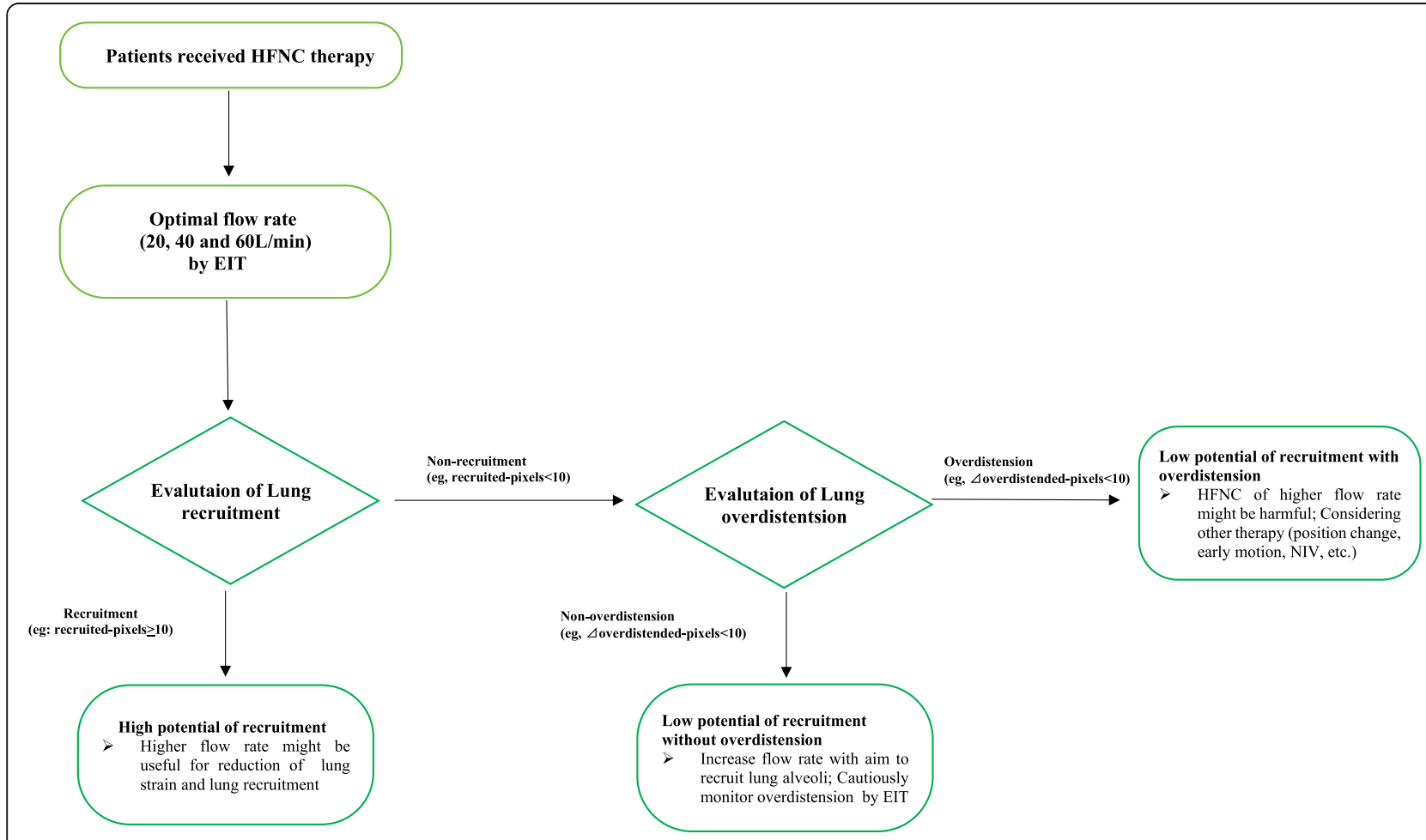

Fig. 3 Conceptual schematic for using EIT to guide HFNC therapy. NIV, non-invasive ventilation 
therapy in postoperative patients. Further study is required to investigate the relationship of diaphragm protection and lung recruitment during the HFNC therapy. Combining diaphragm protection and lung recruitment might be more suitable and effective. Sixth, air trapping may exist in smokers, which may affect the overdistension results; however, we did not detect the phenomenon in this study. Seventh, with the aim to titrate an optimal flow rate in practical terms, the three phases of different flow rates were stepwise elevated but not be randomized. To control the carryout effect, the flow rate gradually increased (from $0 \rightarrow 20 \rightarrow 40 \rightarrow 60 \mathrm{~L} / \mathrm{min}$ ). An increased flow rate was accompanied by the elevation of airway pressure, and theoretically, the former (low) flow rate had little effect on the later (high) flow rates. However, $20 \mathrm{~min}$ in each period should have been sufficient to achieve a stable effect on lung volume and gas exchange in this study. Parke et al. reported that airway pressure can stabilize in $15 \mathrm{~min}$ during HFNC therapy [36]. Eighth, some might argue regarding the difference of air trapping and lung overdistension by EIT. Overinflated regions of lungs might sometimes appear similar to air trapping. Air trapping is defined as lung overdistension due to flow limitation in COPD/asthma/ARDS [37, 38]. Two cases that reported using EIT technology could be useful to adjust an individual extra-PEEP of mechanical ventilation settings in severe asthma patients [38, 39]. In the present study, we did not find any signs of air trapping by EIT (flow limitation) as the flow rate increased. Hence, the potential effect of air trapping may not impact our conclusions.

\section{Conclusions}

There were diverse responses of lung regional ventilation and aeration (recruitment, non-recruitment, and overdistension) to HFNC. However, the effect varied among individuals. Identification of lung recruitment, lung nonrecruitment, and overdistension by EIT might be helpful to guide HFNC therapy in post-extubation situations. Further study will be required to validate the meaning of this classification in clinical practice.

\section{Supplementary information}

Supplementary information accompanies this paper at https://doi.org/10. 1186/s13054-020-2809-7.

Additional file 1. Deduction procedure and calculation formula of lung strain.

\section{Abbreviations}

ANOVA: Analysis of variance; BMI: Body mass index; ElT: Electrical impedance tomography; $\mathrm{FiO}_{2}$ : Fraction of inspired oxygen; Gl: Global inhomogeneity; HFNC: High-flow nasal cannula; HR: Heart rate; MAP: Mean arterial pressure; PI: Perfusion index; ROls: Regions of interest; RR: Respiratory rate;

RVD: Regional ventilation delay; $\mathrm{SPO}_{2}$ : Peripheral oxygen saturation;
$\Delta E E L I$ : Change of end-expiratory lung impedance; $\Delta T \mathrm{~V}$ : Change of tidal variation

Acknowledgements

The authors thank all the subjects for their participation in this study.

Promotion

None

\section{Authors' contributions}

$\mathrm{RZ}$ takes responsibility for (is the guarantor of) the content of the manuscript, including the data and analysis. RZ and $\mathrm{HH}$ had full access to all of the data in the study and take responsibility for the integrity of the data and the accuracy of the data analysis, including and especially any adverse effects. LY, XZ, XW, YC, SY, and ZZ contributed substantially to the study design, data analysis and interpretation, and the writing of the manuscript. All authors read and approved the final manuscript.

\section{Funding}

None

\section{Availability of data and materials}

The datasets used and/or analyzed during the current study are available from the corresponding author on reasonable request.

\section{Ethics approval and consent to participate}

The ethics review board of Peking Union Medical College Hospital approved the study protocol, and written informed consent was obtained from all participants before enrollment.

\section{Consent for publication}

Not applicable

\section{Competing interests}

Zhanqi Zhao receives a consulting fee from Dräger Medical. All other authors declare that they have no competing interests.

\section{Author details}

${ }^{1}$ Department of Critical Care Medicine, Peking Union Medical College Hospital, Peking Union Medical College, Chinese Academy of Medical Sciences, 1 Shuaifuyuan, Dongcheng District, Beijing, China. ${ }^{2}$ Department of Biomedical Engineering, Fourth Military Medical University, Xi'an, China. ${ }^{3}$ Institute of Technical Medicine, Furtwangen University,

Villingen-Schwenningen, Germany.

Received: 9 October 2019 Accepted: 25 February 2020

Published online: 06 March 2020

\section{References}

1. Hernandez G, Vaquero C, Gonzalez P, Subira C, Frutos-Vivar F, Rialp G, Laborda C, Colinas L, Cuena R, Fernandez R. Effect of postextubation highflow nasal cannula vs conventional oxygen therapy on reintubation in lowrisk patients: a randomized clinical trial. JAMA. 2016;315(13):1354-61.

2. Inata $Y$, Takeuchi M. Complex effects of high-flow nasal cannula therapy on hemodynamics in the pediatric patient after cardiac surgery. J Intensive Care. 2017:5:30.

3. Mauri T, Alban L, Turrini C, Cambiaghi B, Carlesso E, Taccone P, Bottino N, Lissoni A, Spadaro S, Volta CA, et al. Optimum support by high-flow nasal cannula in acute hypoxemic respiratory failure: effects of increasing flow rates. Intensive Care Med. 2017:43(10):1453-63.

4. Braunlich J, Beyer D, Mai D, Hammerschmidt S, Seyfarth HJ, Wirtz H. Effects of nasal high flow on ventilation in volunteers, COPD and idiopathic pulmonary fibrosis patients. Respiration. 2013;85(4):319-25.

5. Frat JP, Thille AW, Mercat A, Girault C, Ragot S, Perbet S, Prat G, Boulain T,

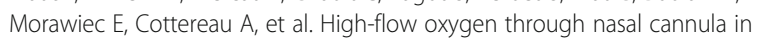
acute hypoxemic respiratory failure. N Engl J Med. 2015;372(23):2185-96.

6. Mauri T, Eronia N, Turrini C, Grasselli G, Bellani G, Pesenti A. High flow nasal cannula improves lung aeration and enhances $\mathrm{Co} 2$ removal in hypoxemic critically ill patients. Intensive Care Med Exper. 2015;3(Suppl 1):A176.

7. Corley A, Caruana LR, Barnett AG, Tronstad O, Fraser JF. Oxygen delivery through high-flow nasal cannulae increase end-expiratory lung volume and 
reduce respiratory rate in post-cardiac surgical patients. Br J Anaesth. 2011; 107(6):998-1004

8. Maggiore SM, Idone FA, Vaschetto R, Festa R, Cataldo A, Antonicelli F, Montini L, De Gaetano A, Navalesi P, Antonelli M. Nasal high-flow versus Venturi mask oxygen therapy after extubation. Effects on oxygenation, comfort, and clinical outcome. Am J Respir Crit Care Med. 2014;190(3):282-8.

9. Parke RL, Bloch A, McGuinness SP. Effect of very-high-flow nasal therapy on airway pressure and end-expiratory lung impedance in healthy volunteers. Respir Care. 2015;60(10):1397-403.

10. Perbet $\mathrm{S}$, Bertran $\mathrm{S}$, Longere B, Pereira B, Futier E, Constantin JM. Effect of high-flow nasal cannula oxygen on diaphragmatic excursion and lung volumes determined by electrical impedance tomography. Intensive Care Med Exper. 2015;3(Suppl 1):A165

11. Stephan F, Barrucand B, Petit P, Rezaiguia-Delclaux S, Medard A, Delannoy B, Cosserant B, Flicoteaux G, Imbert A, Pilorge C, et al. High-flow nasal oxygen vs noninvasive positive airway pressure in hypoxemic patients after cardiothoracic surgery: a randomized clinical trial. JAMA. 2015;313(23):2331-9.

12. Ni YN, Luo J, Yu H, Liu D, Liang BM, Liang ZA. The effect of high-flow nasa cannula in reducing the mortality and the rate of endotracheal intubation when used before mechanical ventilation compared with conventional oxygen therapy and noninvasive positive pressure ventilation. A systematic review and meta-analysis. Am J Emerg Med. 2018;36(2):226-33.

13. Xu F, Fei D, Jiang L, Jiang P. Discussion on "effects of high-flow nasal cannula on the work of breathing in patients recovering from acute respiratory failure". Crit Care Med. 2018;46(3):e274-5.

14. Mauri T, Turrini C, Eronia N, Grasselli G, Volta CA, Bellani G, Pesenti A. Physiologic effects of high-flow nasal cannula in acute hypoxemic respiratory failure. Am J Respir Crit Care Med. 2017;195(9):1207-15.

15. Carratala JM, Diaz Lobato S, Brouzet B, Mas-Serrano P, Espinosa B, Llorens P. Efficacy and safety of high-flow nasal cannula oxygen therapy in patients with acute heart failure. Emergencias. 2018;30(6):395-9.

16. Piastra M, Morena TC, Antonelli M, Conti G. Uncommon barotrauma while on high-flow nasal cannula. Intensive Care Med. 2018;44(12):2288-9.

17. Gattinoni L, Marini JJ, Collino F, Maiolo G, Rapetti F, Tonetti T, Vasques F, Quintel M. The future of mechanical ventilation: lessons from the present and the past. Crit Care. 2017;21(1):183.

18. Liu S, Tan L, Moller K, Frerichs I, Yu T, Liu L, Huang Y, Guo F, Xu J, Yang Y, et al. Identification of regional overdistension, recruitment and cyclic alveolar collapse with electrical impedance tomography in an experimental ARDS model. Crit Care. 2016;20(1):119.

19. Franchineau G, Brechot N, Lebreton G, Hekimian G, Nieszkowska A, Trouillet JL, Leprince P, Chastre J, Luyt CE, Combes A, et al. Bedside contribution of electrical impedance tomography to setting positive end-expiratory pressure for extracorporeal membrane oxygenation-treated patients with severe acute respiratory distress syndrome. Am J Respir Crit Care Med. 2017; 196(4):447-57.

20. Riera J, Perez P, Cortes J, Roca O, Masclans JR, Rello J. Effect of high-flow nasa cannula and body position on end-expiratory lung volume: a cohort study using electrical impedance tomography. Respir Care. 2013;58(4):589-96.

21. Roy A. Estimating correlation coefficient between two variables with repeated observations using mixed effects model. Biom J. 2006;48:286-301.

22. McCulloch CE, Searle SR. Generalised, linear and mixed models. New York: Wiley; 2001.

23. S.W. Greenhouse, S. Geisser. On methods in the analysis of profile data Psychometrika, 2 (1959), 95-112. DOl:https://doi.org/10.1007/BF02289823.

24. Carvalho AR, Pacheco SA, de Souza Rocha PV, Bergamini BC, Paula LF, Jandre FC, Giannella-Neto A. Detection of tidal recruitment/overdistension in lung-healthy mechanically ventilated patients under general anesthesia. Anesth Analg. 2013;116(3):677-84.

25. Terragni PP, Rosboch G, Tealdi A, Corno E, Menaldo E, Davini O, Gandini G, Herrmann P, Mascia L, Quintel M, et al. Tidal hyperinflation during low tida volume ventilation in acute respiratory distress syndrome. Am J Respir Crit Care Med. 2007;175(2):160-6.

26. Bellani G, Guerra L, Musch G, Zanella A, Patroniti N, Mauri T, Messa C, Pesenti A. Lung regional metabolic activity and gas volume changes induced by tidal ventilation in patients with acute lung injury. Am J Respir Crit Care Med. 2011;183(9):1193-9.

27. Gonzalez-Lopez A, Garcia-Prieto E, Batalla-Solis E, Amado-Rodriguez L, Avello $\mathrm{N}$, Blanch L, Albaiceta GM. Lung strain and biological response in mechanically ventilated patients. Intensive Care Med. 2012;38(2):240-7.
28. Plotnikow GA, Thille AW, Vasquez DN, Pratto RA, Quiroga CM, Andrich ME, Dorado JH, Gomez RS, D'Annunzio PA, Scapellato JL, et al. Effects of highflow nasal cannula on end-expiratory lung impedance in semi-seated healthy subjects. Respir Care. 2018;63(8):1016-23.

29. Caruana LR, Barnett AG, Tronstad O, Paratz JD, Chang AT, Fraser JF. Global tidal variations, regional distribution of ventilation, and the regional onset of filling determined by electrical impedance tomography: reproducibility. Anaesth Intensive Care. 2017;45(2):235-43.

30. Roca O, Messika J, Caralt B, Garcia-de-Acilu M, Sztrymf B, Ricard JD, Masclans $J R$. Predicting success of high-flow nasal cannula in pneumonia patients with hypoxemic respiratory failure: the utility of the ROX index. J Crit Care. 2016;35:200-5.

31. Mauri T, Carlesso E, Spinelli E, Turrini C, Corte FD, Russo R, Ricard JD, Pesenti A, Roca O, Grasselli G. Increasing support by nasal high flow acutely modifies the ROX index in hypoxemic patients: a physiologic study. J Crit Care. 2019;53:183-5.

32. Roca O, Caralt B, Messika J, Samper M, Sztrymf B, Hernandez G, Garcia-deAcilu M, Frat JP, Masclans JR, Ricard JD. An index combining respiratory rate and oxygenation to predict outcome of nasal high-flow therapy. Am J Respir Crit Care Med. 2019;199(11):1368-76.

33. Corley A, Bull T, Spooner AJ, Barnett AG, Fraser JF. Direct extubation onto high-flow nasal cannulae post-cardiac surgery versus standard treatment in patients with a $\mathrm{BMI}>/=30$ : a randomised controlled trial. Intensive Care Med. 2015;41(5):887-94.

34. Demoule A, Rello J. High flow oxygen cannula: the other side of the moon. Intensive Care Med. 2015:41(9):1673-5.

35. Hahn G, Just A, Dudykevych T, Frerichs I, Hinz J, Quintel M, Hellige G. Imaging pathologic pulmonary air and fluid accumulation by functional and absolute EIT. Physiol Meas. 2006;27(5):S187-98.

36. Parke RL, Eccleston ML, McGuinness SP. The effects of flow on airway pressure during nasal high-flow oxygen therapy. Respir Care. 2011;56(8): $1151-5$.

37. Mauri T, Bellani G, Salerno D, Mantegazza F, Pesenti A. Regional distribution of air trapping in chronic obstructive pulmonary disease. Am J Respir Crit Care Med. 2013;188(12):1466-7.

38. Kostakou E, Barrett N, Camporota L. Electrical impedance tomography to determine optimal positive end-expiratory pressure in severe chronic obstructive pulmonary disease. Crit Care. 2016;20(1):295.

39. Yonis H, Mortaza S, Baboi L, Mercat A, Guérin C. Expiratory flow limitation assessment in ARDS patients. A Reappraisal. Am J Respir Crit Care Med. 2018;198(1):131-4.

\section{Publisher's Note}

Springer Nature remains neutral with regard to jurisdictional claims in published maps and institutional affiliations.

Ready to submit your research? Choose BMC and benefit from:

- fast, convenient online submission

- thorough peer review by experienced researchers in your field

- rapid publication on acceptance

- support for research data, including large and complex data types

- gold Open Access which fosters wider collaboration and increased citations

- maximum visibility for your research: over $100 \mathrm{M}$ website views per year

At $\mathrm{BMC}$, research is always in progress.

Learn more biomedcentral.com/submission 